\title{
HUBUNGAN ANTARA AKTIVITAS FISIK DENGAN DYSMENORRHEA PRIMER PADA ATLET DAN NON ATLET RENANG REMAJA PUTRI USIA 12 - 16 TAHUN DI CLUB ORCA GAJAHYANA KOTA MALANG
}

\author{
Anik Sri Purwanti ${ }^{1}$, Rani Safitri ${ }^{2}$ \\ ${ }^{1}$ nicksetiawan2601@gmail.com, ${ }^{2}$ raniandriatno@gmail.com \\ ${ }^{1,2}$ Prodi D-III Kebidanan, Poltekkes RS dr. Soepraoen Malang \\ J1. S. Supriadi no 22 Sukun - Kota Malang
}

\begin{abstract}
Abstrak
Pematangan seksual remaja putri berupa menstruasi yang terkadang dapat menimbulkan keluhan yang menyertai, salah satunya dysmenorrhea primer merupakan keluhan yang sering terjadi saat menstruasi dan masih tergolong keluhan fisiologis timbul setidaknya 45\%-90\% wanita produktif mengalami dysmenorrhea. Salah satu cara untuk mengatasi dysmenorrhea dengan exercise/ latihan fisik akan menghasilkan hormon endorphin yang berfungsi sebagai obat penenang alami. Penelitian ini menggunakan rancangan case control pendekatan retrospektif. Sampel penelitian remaja putri usia 12-16 tahun di Club ORCA kolam renang Gajahyana Malang dan remaja putri di SMP Islam Ash-Syafi'iyyah Kebonagung sebagai kelompok control yang memenuhi kriteria inklusi (purposive sampling). Instrumen menggunakan lembar kuisioner. Hasil penelitian didapatkan dari 24 responden, sebanyak $46 \%$ dengan aktifitas fisik berat. Dari jumlah tersebut sebagian besar responden (33\%) tidak mengalami dysmenorrhea primer, dan sebagian kecil responden (17\%) dengan aktifitas fisik berat dan sedang mengalami dysmenorrhea primer. Sedangkan responden non atlet yang seluruhnya memiliki aktifitas fisik ringan sebanyak 12 orang $(50 \%)$, 9 orang diantaranya mengalami dysmenorrhea primer $(38 \%)$. Hasil uji statistik spearman rank didapatkan $\mathrm{p}<0,05(0,02<0,05)$ maka disimpulkan $\mathrm{H}_{1}$ diterima artinya ada hubungan antara aktifitas fisik dengan dysmenorrhea primer pada atlet dan non atlet. Disarankan kepada remaja putri agar memantau aktivitas harian juga menambahkan olahraga secara teratur agar terhindar dari dysmenorrhea primer.
\end{abstract}

Kata Kunci: Aktifitas Fisik, Dysmenorrhea Primer, Atlet Renang, Non Atlet

\begin{abstract}
Female sexual maturation in the form of menstruation which sometimes can lead to complaints that accompany, one of which is primary dysmenorrhea is a complaint that often occurs during menstruation and is still classified as physiological complaints arise at least $45 \%-90 \%$ of productive women experience dysmenorrhea. One way to overcome dysmenorrhea by physical exercise / exercise will produce the hormone endorphin which functions as a natural sedative. This study uses a retrospective approach case control design. The research sample was young women aged 12-16 years at Club ORCA swimming pool Gajahyana Malang and young women at Ash-Syafi'iyyah Islamic Middle School Kebonagung as a control group that met the inclusion criteria (purposive sampling). The instrument uses a questionnaire sheet. The results of the study were obtained from 24 respondents, $46 \%$ with severe physical activity. Of these, the majority of respondents (33\%) did not experience primary dysmenorrhea, and a small proportion of respondents (17\%) had severe physical activity and were experiencing primary dysmenorrhea. While non athlete respondents who all had mild physical activity as many as 12 people (50\%), 9 of them experienced primary dysmenorrhea (38\%). The results of the Spearman rank statistical test obtained $p<0.05(0.02<0.05)$, then concluded H1 was accepted meaning that there was a relationship between physical activity and primary dysmenorrhea in athletes and non-athletes. It is recommended that young women monitor daily activities as well as add regular exercise to avoid primary dysmenorrhea..
\end{abstract}

Keywords: Physical Activity, Primary Dysmenorrhea, Swimming Athletes, Non Athletes 


\section{Pendahuluan}

Masa remaja adalah periode yang paling rawan dalam perkembangan hidup seorang manusia setelah ia mampu bertahan hidup (survive), dimana secara fisik ia akan mengalami perubahan fisik yang spesifik dan secara psikologik. Dalam perubahan fisik salah satu nya yaitu terjadi pematangan secara seksual. Pematangan secara seksual merupakan suatu periode dimana seorang anak mengalami perubahan fisik, hormonal, dan seksual serta mampu mengadakan proses reproduksi ${ }^{[1]}$.

Prevalensi angka kejadian dysmenorrhea sangat tinggi dan setidaknya 45\%-90\% wanita mengalami dysmenorrhea sepanjang tahun-tahun reproduktif. Sedangkan prevalensi dysmenorrhea primer sendiri masih mencapai angka $90 \%$ pada wanita yang aktif ${ }^{[2]}$. Angka kejadian dysmenorrehea tipe primer di Indonesia adalah sekitar $54,89 \%$, sedangkan sisanya adalah penderita dengan tipe sekunder ${ }^{[1]}$. Di Jawa Timur jumlah remaja putri yang mengalami dysmenorrhea yaitu yang berusia 10-24 tahun adalah sebesar 56.598 jiwa, $(1,31 \%)^{[3]}$. Di Surabaya di dapatkan $1,07 \%$ sampai $1,31 \%$ dari jumlah penderita dysmenorrhea datang kebagian kebidanan.

Dysmenorrhea primer dapat disebabkan karena ada beberapa faktor yang menyebabkan antara lain faktor kejiwaan atau gangguan psikis, faktor konstitusi, serta faktor alergi ${ }^{[4]}$. Menurut Smeltzer (2002) didalam Nugroho [5], dysmenorrhea primer muncul sebagai akibat dari manifestasi adanya pembentukan dari hormone prostaglandin yang secara berlebihan sehingga bisa menyebabkan uterus berkontraksi secara berlebihan. Selain itu juga bisa mengakibatkan vasospasme arteriolar. Namun, dengan bertambahnya usia wanita, nyeri dysmenorrhea akan semakin menurun atau bahkan bisa hilang setelah melahirkan anak.

Strategi baru untuk mengatasi dysmenorrhea adalah dengan melakukan exercisel latihan fisik tubuh akan menghasilkan hormon endorphin ${ }^{[6]}$. Hormon endorphin akan dihasilkan diotak dan susunan saraf tulang belakang. Hormon ini dapat berfungsi sebagai obat penenang alami, sehingga menimbulkan rasa nyaman. Menurut ${ }^{[4]}$, olahraga secara teratur dapat memperlancar aliran darah pada otot disekitar rahim sehingga akan meredakan rasa nyeri pada saat haid.

Berdasarkan jurnal penelitian dari Novia ${ }^{[7]}$ tentang Faktor Risiko yang Mempengaruhi Kejadian Dismenore Primer menunjukkan bahwa kebiasaan responden yang mempunyai kebiasaan olahraga sebagian besar mengalami dysmenorrhea primer. Hasil penelitian ini berbeda dengan pendapat yang menyatakan bahwa kurang atau tidak pernah olahraga akan meningkatkan kemungkinan terjadinya dysmenorrhea primer. ${ }^{[8]}$.

Berdasarkan hasil studi pendahuluan di club ORCA didapatkan data anggota sebanyak 30 orang remaja putri rentang usia 12-14 tahun, dan yang telah mengalami menstruasi ada 27 orang. Penelitian ini bertujuan untuk mengetahui hubungan aktivitas fisik dengan dysmenorrhea primer pada atlet renang dan non atlet remaja putri usia 12 - 16 tahun.

\section{Metode penelitian}

\section{a. Responden}

Penelitian ini menggunakan 24 orang responden yang terdiri dari 12 orang remaja putri di Club ORCA kolam renang Gajahyana kota Malang dan 12 orang responden non atlet $12-16$ tahun yang bukan merupakan atlet renang. Kesemua responden dipilih dengan kriteria inklusi antara lain remaja putri dengan usia 12 - 16 tahun, telah mendapatkan menstruasi teratur setiap bulannya, bagi responden atlet renang telang aktif sebagai atlet renang selama 1 tahun terakhir di Club ORCA kolam renang Gajahyana Kota Malang, serta seluruh responden yang bersedia menjadi responden. 


\section{b. Pengukuran Aktifitas Fisik}

Untuk mengetahui tingkat aktifitas responden dimana remaja putri yang memiliki aktifitas fisik sebagai atlit renang yang tingkat aktifitasnya dapat diukur dengan menggunakan instrument pengukuran aktifitas fisik yaitu PAL (Physical Activity Level). Dengan kategori aktivitas ringan (1.40-1.69), aktivitas sedang(1.70-1.99), aktivitas berat (2.00-2.40).

\section{c. Pengukuran Dysmenorrhea Primer \\ Untuk mengetahui kejadian} Dysmenorrhea primer yang terjadi pada saat menstruasi berupa nyeri pada perut bagian bawah menjalar ke punggung bagian bawah dan tungkai. Nyeri dirasakan sebagai kram yang hilang timbul atau sebagai nyeri tumpul yang terus-menerus ada. Biasanya nyeri mulai timbul sesaat sebelum atau selama menstruasi berlangsung menggunakan lembar kuisioner yang diisi sendiri oleeh responden dengan dipandu oleh peneliti. Dengan kategori tidak mengalami dysmenorrhea primer dan yang mengalami dysmenorrhea primer.

\section{Hasil penelitian dan Pembahasan}

a. Data Umum Responden

1) Usia Responden

Tabel 1 Distribusi Frekuensi Usia Responden

\begin{tabular}{lccc}
\hline No & Umur & Frek & \% \\
\hline 1. & $11-13$ th & 3 & 9 \\
2. & $14-16$ th & 21 & 91 \\
\hline \multicolumn{2}{l}{ Jumlah } & 24 & 100 \\
\hline
\end{tabular}

Berdasarkan tabel 1 diperoleh data bahwa dari 24 responden tercatat sebagian besar dari responden $(91 \%)$ berusia antara 14-16 tahun, dan hampir setengah dari responden $(9 \%)$ berusia 11-13 tahun.

2) Lama Mengikuti Club

Tabel 2 Distribusi Frekuensi Lama Mengikuti Club Responden Di Kolam Renang Gajayana Club

\begin{tabular}{cccc} 
& \multicolumn{2}{c}{ ORCA Kota Malang } & Pada \\
Bulan Februari 2018 & \\
\hline No & $\begin{array}{c}\text { Lamanya } \\
\text { Mengikuti } \\
\text { Club }\end{array}$ & Frek & $\%$ \\
\hline 1. & & \\
2. & $6-10$ tahun & 2 & 17 \\
3. & $>10$ tahun & 8 & 66 \\
\hline & Jumlah & 12 & 17 \\
\hline
\end{tabular}

Berdasarkan tabel 2 diperoleh data bahwa dari 12 responden tercatat sebagian besar (66\%) responden lama mengikuti club 6-10 tahun, (17\%) responden lama mengikuti club $<5$ tahun tahun dan $(17 \%)$ responden lama mengikuti club $>10$ tahun.

b. Data Khusus

1) Aktifitas Fisik

Tabel 3 Distribusi Frekuensi Hasil Pengukuran Aktifitas Fisik Dengan PAL Pada Remaja Putri Sebagai Atlet dan Non Atlet Renang

\begin{tabular}{lccccc}
\hline N & $\begin{array}{c}\text { Kategori } \\
\text { o }\end{array}$ & $\begin{array}{c}\text { Aktifitas } \\
\text { Fisik }\end{array}$ & $\begin{array}{c}\text { Atlet } \\
\text { Renang }\end{array}$ & \multicolumn{2}{c}{$\begin{array}{c}\text { Non } \\
\text { Atlet } \\
\text { Renang }\end{array}$} \\
\cline { 3 - 6 } & & F & \% & F & $\%$ \\
\hline 1. & Ringan & 0 & 0 & 11 & 65 \\
2. & Sedang & 1 & 8 & 1 & 35 \\
3. & Berat & 11 & 92 & 0 & 0 \\
\hline \multicolumn{2}{c}{ Jumlah } & 12 & 100 & 12 & 100
\end{tabular}

Berdasarkan klasifikasi hasil pengukuran Aktifitas Fisik Dengan PAL pada tabel 4 dari 12 responden remaja putri sebagai atlet renang didapati hampir seluruh responden (92\%) dengan hasil pengukuran aktifitas fisik berat. Sedangkan 12 responden remaja putri sebagai non atlet renang didapati sebagian besar responden $65 \%$ dengan hasil pengukuran aktifitas fisik ringan.

Dari hasil penelitian terhadap 12 hasil pengukuran Aktifitas Fisik Dengan PAL didapati hampir seluruh responden $(75 \%)$ dengan hasil pengukuran aktifitas fisik berat dan sebagian kecil responden (25\%) responden dengan hasil pengukuran 
aktifitas fisik sedang. Perbedaan yang siginifikan antara aktivitas fisik berat dan ringan adalah berdasarkan dari energi yang dikeluarkan. Semakin banyak energi atau tenaga yang menimbulkan pengeluaran keringat secara aktif dan intens maka aktivitas semakin berat terjadi. Ini sesuai dengan teori Physical Activity Level (FAO 2001 karena didasarkan pada Report of a Joint FAO/WHO/UNU Expert Consultation Rome, 17-24 October 2001) yang kemudian dikutip oleh Bagga dan Kulkarni (2000) ${ }^{[9]}$ dalam bukunya mengenai aktifitas fisik yang menyebutkan bahwa menyatakan bahwa remaja putri yang melakukan olahraga, seperti voli, bulutangkis, dan renang dengan intensitas tidak teratur cenderung mengalami dysmenorrhea dibandingkan remaja yang melakukan olahraga teratur. Untuk menghitung kebutuhan energi diperlukan besarnya aktivitas fisik yang dilakukan oleh seseorang berdasarkan gaya hidup yang biasa dilakukannya sehari-hari. Oleh sebab itu pengukuran aktivitasnya haruslah dapat menggambarkan gaya hidupnya.

Besarnya aktivitas fisik yang dilakukan seseorang selama 24 jam dinyatakan dalam PAL (Physical Activity Level) atau tingkat aktivitas fisik (Human energy requirements, 2004). Aktivitas fisik adalah setiap gerakan tubuh yang dihasilkan oleh otot rangka yang memerlukan pengeluaran energi. Aktivitas fisik yang tidak ada (kurangnya aktivitas fisik) merupakan faktor risiko independen untuk penyakit kronis, dan secara keseluruhan diperkirakan menyebabkan kematian secara global [10].

\section{2) Dysmenorrhea Primer \\ Tabel 4 Distribusi Frekuensi Dysmenorrhea Primer dalam 3 siklus terakhir Pada}

Remaja Putri Sebagai Atlet dan Non Atlet Renang

\begin{tabular}{cccccc}
\hline N & Dysmeno & \multicolumn{2}{c}{$\begin{array}{c}\text { Atlet } \\
\text { o }\end{array}$} & $\begin{array}{c}\text { Nonhea } \\
\text { Primer }\end{array}$ & \multicolumn{2}{c}{$\begin{array}{c}\text { Renang } \\
\text { Rentlet }\end{array}$} & \% & F & \% \\
\hline 1. & Ya & 4 & 33 & 9 & 65 \\
2. & Tidak & 8 & 67 & 3 & 35 \\
\hline & Jumlah & 12 & 100 & 12 & 100 \\
\hline
\end{tabular}

Berdasarkan klasifikasi dysmenorrhea primer pada tabel 5 dari 12 responden remaja putri sebagai atlet renang didapati sebagian besar dari responden (67\%) tidak mengalami dysmenorrhea primer. Sedangkan 12 responden remaja putri sebagai non atlet renang didapati sebagian besar responden $65 \%$ mengalami dysmenorrhea primer dalam 3 siklus terakhir.

Pada penelitian ini terjadinya dysmenorrhea primer pada 12 responden yang merupakan atlet renang didapatkan sebagian besar dari responden (67\%) dengan aktifitas fisik berat tidak mengalami dysmenorrhea primer dalam 3 siklus terakhir, dan hanya (33\%) responden dengan aktifitas fisik berat dan sedang yang mengalami dysmenorrhea primer dalam 3 siklus terakhir. Dimana responden mengalami haid atau menstruasi dengan adanya nyeri pada perut dan juga nyeri pada pinggang

Menurut American College of Sport Medicine (ACSM) dalam Wiarto (2013) $)^{[11]}$ menyatakan bahwa kebugaran fisik merupakan suatu kemampuan seseorang untuk melakukan aktifitas fisik. Dimasa seseorang tersebut selain fisiknya akan bugar, juga system metabolismenya akan bagus dan secara substansial dapat menghasilkan energy yang dibutuhkan oleh tubuh saat melakukan aktivitas fisik. Selain itu memiliki tubuh yang bugar dapat mengurangi faktor resiko berbagai macam penyakit. Salah satu ketidaknyaman yang terjadi akibat dari kurangnya aktivitas pada wanita 
khususnya remaja putri adalah terjadinya dysmenorrhea primer yang menyertai peristiwa menstruasi. Selain itu, menurut Rosa (2010) bahwa untuk mencegah terjadinya dysmenorrhea primer dapat dengan melakukan latihan peregangan maupun relaksasi. Dimana kegiatan tersebut dapat mengurangi kadar prostaglandin, melepaskan endorfin, meningkatkan aliran darah dan mengurangi spasme otot. Juga olahraga yang teratur dapat membantu menyeimbangkan system organ dan sirkulasi hormone dalam tubuh.

c. Hubungan Aktifitas Fisik dengan Dysmenorrhea Primer Pada Remaja Putri Sebagai Atlet dan Non Atlet Renang.

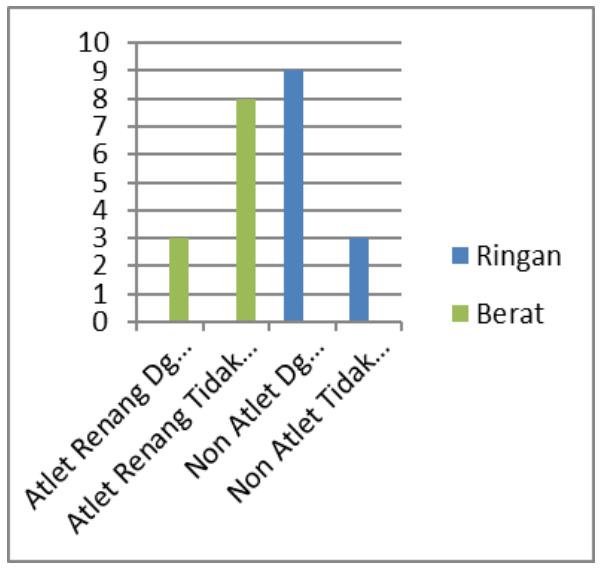

Gambar 1. Grafik Aktifitas Fisik dengan Dysmenorrhea Primer Pada Remaja Putri Sebagai Atlet dan Non Atlet Renang.

Berdasarkan diagram diatas menunjukkan dari 24 responden (atlet renanng dan non atlet) yang tercatat sebagian responden $(46 \%)$ dengan aktifitas fisik berat, dari jumlah tersebut sebagian besar responden (33\%) tidak mengalami dysmenorrhea primer, dan sebagian kecil responden (17\%) dengan aktifitas fisik berat dan sedang yang mengalami dysmenorrhea primer. Sedangkan pada responden non atlet yang seluruhnya memiliki aktifitas fisik ringan sebanyak 12 orang $(50 \%), 9$ orang diantaranya mengalami dysmenorrhea primer $(38 \%)$.

Berdasarkan uji statistik korelasi Spearman Rank rho $\left(\mathrm{r}_{\mathrm{s}}\right)$ dengan dibantu program SPSS versi 16 for windows didapatkan p 0,02 , dan $\alpha$ 0,05 . Sedangkan taraf signifikan 0,05 adalah 0,03 . Oleh karena $\mathrm{p}<0,05(0,02$ $<0,05)$ maka dapat disimpulkan bahwa $\mathrm{H}_{1}$ diterima, artinya ada hubungan antara aktifitas fisik dengan dysmenorrhea primer pada atlet dan non atlit di Kolam Renang Gajayana Club Orca Kota Malang.

Peneliti juga meneukan bahwa dengan remaja putri tersebut melakukan aktivitas tambahan selain aktivitas harian (misalkan sebagi atlet olahraga dimana memiliki aktivitas olahraga secara teratur) akan mengurangi terjadinya dysmenorrhea primer. Hal ini sesuai dengan pendapat (Anugoro, D dan Wulandari, 2011) bahwa dengan melakukan olahraga secara teratur setidaknya 30 menit setiap hari, olahraga yang dipilih tidak harus olahraga berat. Anda bisa sekedar berjalan-jalan santai selama 30 menit, jogging ringan, senam ringan, berenang (Sejati, 2009), maupun bersepeda, pilihlah yang paling sesuai dengan kondisi masing-masing. Olahraga secara teratur dapat memperlancar aliran darah pada otot disekitar rahim sehingga akan meredakan rasa nyeri pada saat haid. Karena salah satu faktor penyebab terjadinya dysmenorrhea primer yaitu adanya aktifitas fisik yang berat akan menurunkan kadar hormone estrogen dibuat di dalam ovarium, atau akibat adanya gangguan penghantaran impuls dari dalam otak kedalam ovarium. Rendahnya kadar estrogen dapat mempengaruhi karakteristik fisik, perilaku, dan kesuburan. Lakukan minimal 30 menit olahraga sedang untuk kesehatan jantung, selain itu bisa melakukan olah raga selama 60 menit untuk mencegah kenaikan berat badan dan 90 menit untuk menurunkan berat badan. 


\section{Kesimpulan}

Berdasarkan penelitian yang dilakukan dapat disimpulkan bahwa ada hubungan antara aktifitas fisik dengan dysmenorrhea primer pada atlet dan non atlit di Kolam Renang Gajayana Club Orca Kota Malang. Penelitian ini berfokus pada faktor eksternal seperti aktivitas fisik saja, tidak melihat faktorfaktor lain yang mempengaruhi menarche pada remaja putri seperti IMT, pola asupan nutrisi, usia menarche maupun faktor predisposisi lainnya. Sehingga sangat disarankan kepada peneliti selanjutnya untuk mengangkat factor predisposisi lain.

\section{Daftar Pustaka}

[1]. Romaula, S dan Vindari, A, V. Kesehatan Reproduksi Buat Mahasiswa Kebidanan. Yogjakarta: Nuha Medika. 2011.

[2]. Nugroho, T dan Utama, I. Masalah Kesehatan Reproduksi Wanita. Yogyakarta: Nuha Medika. 2014.

[3]. Anonymus. Data BPS Provinsi Jawa Timur. https://jatim.bps.go.id/subject/30/ kesehatan.html. 2010.

[4]. Anugoro, D dan Wulandari, A. Cara Jitu Mengatasi Nyeri Haid. Yogyakarta: C.V Andi. 2011.

[5]. Nugroho, $T$ dan Utama, I. Masalah Kesehatan Reproduksi Wanita. Yogyakarta: Nuha Medika. 2014.

[6]. Anisa, V. The Effect Of Exercises On Primary Dysmenorrhea. Jurnal Majority. 2015.

[7]. Novia, I. Faktor Risiko yang Mempengaruhi Kejadian Dismenore Primer. The Indonesian Journal of Public Health. 2008; 4(2): 96-104.

[8]. Sejati, W. dan S. Sindrom Prementruasi. Yogyakarta: Nuha Medika. 2009.
[9]. Bagga, Amrita and S. Kulkarni. Age at Menarche and Secular Trend In Maharashtrian (Indian Girls). India : Depatements of Anthropology, University of Pune Acta Biologica Szegediensis. . 2000.

[10]. Sjostrom L., Lindroos A.K., et al. Life Style, Diabetic and cardiovascular risk factors 10 years after bariatric surgery. N Engl J Med. 2004; 351(26): 2683-2693

[11]. Wiarto, G. Fisiologi dan Olahraga. Yogyakarta: Graha Ilmu. 2013. 